\title{
STUDI PEMODELAN OPTIMASI TUAS HANDLE REM DEPAN SEPEDA MOTOR YAMAHA V-IXION BERBASIS SIMULASI ELEMEN HINGGA
}

\author{
Supriyanto*, Imam Syafa'at dan Darmanto \\ Jurusan Teknik Mesin Fakultas Teknik Universitas Wahid Hasyim \\ J1. Menoreh Tengah X/22, Sampangan, Semarang 50236 \\ *Email:Supriyanto110593@gmail.com
}

\begin{abstract}
Abstrak
Sepeda motor merupakan salah satu pilihan masyarakat dalam berpergian. Sepeda motor merupakan salah satu jenis kendaraan yang banyak dipilih masyarakat sebagai moda transportasi di zaman modern saat ini. Salah satu jenis sepeda motor tersebut adalah produk Yamaha V-Ixion yang memiliki tampilan bagus. Handle merupakan komponen pada sepeda motor Yamaha V-Ixion yang berfungsi sebagai tuas pengereman terbuat dari material aluminium. Tujuan dari penelitian ini untuk mengetahui tegangan von mises, defleksi, faktor keamanan dan optimasi pada handle. Pada pemodelan menggunakan bantuan Autodesk Inventor Profesional 2014. Material yang digunakan Aluminium 6061 AHC. Pada simulasi dilakukan pembebanan motor jatuh kesamping, setelah melakukan simulasi pembebanan motor jatuh kesamping berisiko besar rawan patah. Pemodelan asli didapatkan tegangan von mises 474,3 MPa, defleksi 2,314 mm, faktor keamanan 0,58. Setelah dilakukan optimasi ketebalan menjadi $2 \mathrm{~mm}$ pada area yang rawan kegagalan (patah) untuk mendapatkan hasil faktor keamanan menjadi 1.21 maka handle aman digunakan.
\end{abstract}

Kata kunci: defleksi, faktor keamanan, handle,optimasi, tegangan

\section{PENDAHULUAN}

Perkembangan transportasi di jaman modern saat ini banyak menggunakan sepeda motor, bahkan sepeda motor sekarang sudah dianggap sebagai kebutuhan primer, banyak berbagai tipe dan merek sepeda motor salah satunya yaitu sepeda motor Yamaha V-Ixion. Salah satu komponen sepeda motor yaitu handle, merupakan komponen penting pada kendaraan sepeda motor, yang di buat dari material baja atau aluminium.

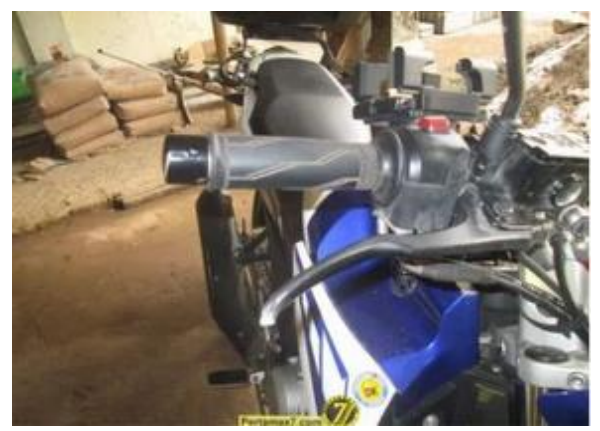

Gambar 1. Kerusakan handle Yamaha VIxion.

(www.pertamax7.com.2015)

Komponen tersebut mempunyai fungsi untuk tuas pengereman sepeda motor. Seiring makin banyaknya sepeda motor dari berbagai merek dan tipe kendaraan dengan desain semakin menarik, handle juga mengalami perubahan bentuk semakin menarik, Tetapi bentuk yang ramping dan menarik tidak menjamin kekuatan handle tersebut. Kadang terjadi kegagalan berupa patah.

Sebuah kasus yang terjadi pada handle motor Yamaha V-Ixion terjadi permasalahan kerusakan yang di sebabkan dari beberapa faktor seperti halnya yang terjadi pada handle Yamaha V-Ixion mengalami patah(Irfan,2015), yang ditunjukkan pada Gambar 1. Dalam penelitian ini, peneliti melakukan analisa pembebanan pada handle dengan metode elemen hingga menganalisis tegangan, defleksi, dan faktor keamanan dengan menggunakan bahan material paduan Aluminium 6061 AHC, menggunakan bantuan Autodesk Inventor Professional 2014.

\section{LANDASAN TEORI}

Ismawanto dkk. (2014) menganalisis tentang simulasi kekuatan material pada Carabiner dengan variasi geometri. Aluminium merupakan bahan logam yang kuat dan ringan sehingga banyak digunakan untuk produksi otomotif seperti foot race dan Carabiner. Carabiner merupakan alat paling penting pada kegiatan panjat tebing. Carabiner memiliki berbagai variasi yang berbeda beda dan memiliki dua jenis yaitu Carabiner screwgate 
(pengunci) dan Carabiner non screwgate (tanpa pengunci). Oleh karena itu penelitian dilakukan secara simulasi variasi geometri pada Carabiner terhadap kekuatan material dengan menggunakan atau menggabungkan software yang berhubungan dengan kekuatan material seperti Solidworks dan Ansys Workbench.

Ansys Workbench adalah perangkat lunak berbasis metode elemen hingga yang dipakai menganalisis masalah-masalah rekayasa (Engineering). Dari hasil analisa tegangan didapatkan data bahwa analisa struktur (statik) dan thermal (perpindahan panas). Dari hasil analisa tegangan didapatkan data bahwa pembebanan yang terjadi menggunakan analisis von misses (stres tarik setara) dapat diketahui tegangan tarik yang terjadi pada Carabiner variasi 1 sebesar $4,3142 \times 10^{5} \mathrm{~Pa}$, tegangan tarik yang terjadi pada Carabiner variasi 2 sebesar 2,4548 X $10^{6} \mathrm{~Pa}$, tegangan tarik yang terjadi pada carabiner variasi 3 sebesar 4,9126 $\mathrm{X} 10^{6} \mathrm{~Pa}$. Dari ketiga variasi geometri pada carabiner, dapat kita ketahui bahwa pengaruh variasi geometri terhadap kekuatan material dengan tegangan tarik atau tegangan von misses $80 \mathrm{~kg}$ adalah geometri pada Carabiner 1 yang paling aman. Tegangan akibat pembebanan sebesar 4,3142 X $10^{5}$ Paskal.

Menurut Khoeron (2016) analisa pada salah satu komponen sepeda motor sangat penting sebelum digunakan karena dari sebuah analisa menghasilkan prediksi kegagalan produk, dalam melakukan analisa beberapa kondisi pembebanan aktual telah dilakukan olehnya, meliputi: pembebanan dengan kondisi pengendara duduk dengan kaki bertumpu pada footstep, pengendara berdiri pada footstep, motor jatuh ke samping, footstep tertabrak dari belakang, footstep tertabrak dari depan dan motor jatuh ke samping dengan dua pengendara. Dimana hasil maksimum didapat pada kondisi motor jatuh ke samping dengan dua pengendara berisiko besar terhadap patahnya footstep holder dengan tegangan von misses 468,9 Mpa dan mempunyai faktor keamanan yang rendah 0,59 dengan defleksi $1,32 \mathrm{~mm}$.

Menurut Ismail (2016) analisa pada salah satu komponen sepeda motor sangat penting sebelum digunakan karena dari sebuah analisa menghasilkan prediksi kegagalan produk, dalam melakukan analisa beberapa kondisi pembebanan aktual telah dilakukan olehnya, diantarnya meliputi: pembebanan dengan kondisi pengendara duduk dengan kaki bertumpu pada footstep, pengendara berdiri pada footstep, motor jatuh ke samping, footstep tertabrak dari belakang, footstep tertabrak dari depan dan motor jatuh ke samping dengan dua pengendara. Dimana hasil maksimum didapatkan pada kondisi motor jatuh ke samping dengan pengendara dengan tegangan maksimum itu adalah 414,6 Mpa. Defleksi maksimum terjadi pada kondisi pembebanan asumsi motor jatuh ke samping dengan pengendara dengan hasil defleksi sebesar $0,3766 \mathrm{~mm}$. Faktor keamanan minimum terjadi pada kondisi pembebanan motor jatuh ke samping dengan pengendara dengan nilai 0,5 .

Menurut Hardiyansyah (2016) analisa pada salah satu komponen sepeda motor sangat penting sebelum digunakan karena dari sebuah analisa menghasilkan prediksi kegagalan produk, dalam melakukan analisa beberapa kondisi pembebanan aktual telah dilakukan olehnya, diantarnya meliputi: pembebanan dengan kondisi pengendara duduk dengan kaki bertumpu pada footstep, pengendara berdiri pada footstep, motor jatuh ke samping, footstep tertabrak dari belakang, dan motor jatuh ke samping dengan dua pengendara. Pada pembebanan dengan kondisi footstep holder tertabrak dari belakang berisiko besar terhadap retaknya footrest, didapatkan tegangan von misses $1009 \mathrm{Mpa}$, defleksi 2,099 mm, faktor keamanan 0,27.

\section{Tegangan von misses}

Menurut teori ini, kegagalan terjadi pada suatu titik di bagian ketika distorsi energi regangan (dalam hal ini adalah energi regangan geser) per satuan volume dalam sistem tegangan bi-aksial mencapai batas energi distorsi yaitu energi distorsi pada titik luluh per satuan volume yang ditentukan dari uji tarik. Secara matematis, teori energi distorsi maksimum dinyatakan sebagai berikut:

$$
\left(\sigma_{\mathrm{t} 1}\right)^{2}+\left(\sigma_{\mathrm{t} 2}\right)^{2}-2 \sigma_{\mathrm{t} 1} \times \sigma_{\mathrm{t} 2}=\left(\frac{\sigma_{\mathrm{yt}}}{\mathrm{FS}}\right)^{2}
$$

Dimana $\sigma_{\mathrm{t} 1} \mathrm{dan}_{\mathrm{t} 2}$ adalah tegangan maksimum dan minimum, $\sigma_{\mathrm{yt}}$ adalah tegangan titik luluh, dan FS adalah faktor keamanan.

\section{Review Dari Solusi Teori Elemen Beam}

Pembebanan pada sebuah struktur di samping mengalami tegangan juga dapat menyebabkan defleksi. Menurut James (2004) Defleksi $v$ adalah perpindahan direksi $y$ pada 
axis beam seperti terlihat pada Gambar defleksi beam.

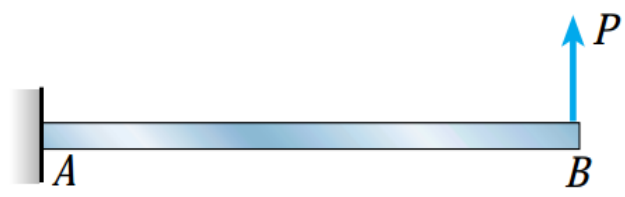

(a)

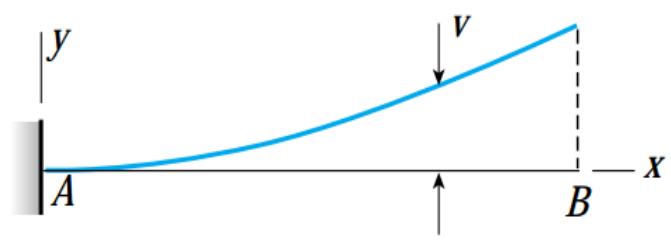

\section{Gambar 2. Defleksi beam (James, 2004)}

Sebelum melanjutkan ke analisis FEM balok, maka ditentukan sebuah solusi untuk masalah yang diperoleh pada teori balok. Defleksi maksimum dari beam $\delta$ max dapat dihitung dengan persamaan(2) berikut (Nakasone dkk., 2006):

$$
\delta_{\max }=\frac{P l_{1}^{3}}{3 E I}\left(1+\frac{3 l_{1}}{l_{2}}\right)
$$

Dimana $\delta_{\max }$ adalah defleksi maksimal, $\mathrm{P}$ adalah beban, $\mathrm{E}$ adalah modulus elastisitas, I adalah momen inersia, $l_{1}$ adalah jarak pembebanan dan $l_{2}$ adalah panjang batang di kurangi dengan jarak pembebanan.

Tegangan tarik maksimum $\sigma_{\max }(x)$ di $x$ arah longitudinal muncul di permukaan atas balok di penampang di $x$ dari dinding:

$$
\sigma_{\max }(x)=\left\{\begin{array}{cc}
\frac{P l_{1}-x}{\mathrm{I}} \frac{h}{2} & \left(0 \leq x \leq l_{1}\right) \\
0 & (0 \leq x)
\end{array}\right.
$$

Dimana $\sigma_{\max }$ adalah defleksi maksimal, $\mathrm{P}$ adalah beban, I adalah momen inersia, $l_{1}$ adalah jarak pembebanan dan $\mathrm{h}$ adalah tinggi batang. I adalah inersia penampang balok. Untuk balok memiliki penampang persegi panjang dari ketinggian $h$ dengan ketebalan $b$, nilai I dapat dihitung dengan persamaan berikut:

$$
I=\frac{b h^{3}}{12}
$$

Dimana I adalah momen inersia, $\mathrm{b}$ adalah lebar batang dan $\mathrm{h}$ adalah tinggi batang.

\section{Faktor keamanan}

Faktor keamanan dalam design harus mempertimbangkan hampir semua faktor yang mungkin meningkatkan terjadinya kegagalan. Menurut Irawan (2009) faktor keamanan dapat dengan cepat diperkirakan menggunakan variasi lima ukuran sebagai berikut:

$\mathrm{FS}=\mathrm{FS}_{\text {material }} \times \mathrm{FS}_{\text {tegangan }} \times \mathrm{FS}_{\text {geometri }} \times \mathrm{FS}_{\text {analisa }}$ kegagalan x FS keandalan

- Perkiraan kontribusi untuk material, $\mathrm{FS}_{\text {material }}$ $\mathrm{FS}=1,0$ jika properti material diketahui. Jika secara eksperimental diperoleh dari pengujian spesimen.

$\mathrm{FS}=1,1$ jika properti material diketahui dari buku panduan atau nilai fabrikasi.

$\mathrm{FS}=1,2-1,4$ jika properti material tidak diketahui.

Faktor keamanan secara umum didefinisikan sebagai rasio dari tegangan maksimum untuk work stress. (Khurmi dan Gupta, 2005).

$$
\mathrm{FS}=\frac{\sigma_{t 1}}{\sigma_{d}}
$$

Dimana FS adalah faktor keamanan, $\sigma_{t 1}$ adalah tegangan maksimum dan $\sigma_{d}$ adalah tegangan desain.

\section{METODE PENELITIAN}

Penelitian di lakukan berdasarkan pendekatan Ilmiah dengan kerangka proses analisa meliputi pemodelan handle dengan menggunakan Autodesk Inventor Professional 2014, bahan yang digunakan dalam metode penelitian adalah alumunium tipe 6061 AHC. Setelah geometri selesai dilakukan pengukuran maka selanjutnya geometri digambar (terlihat pada Gambar 4) dan dianalisis dengan menggunakan Autodesk Inventor Profesional 2014.

Secara umum metode penelitian dapat di gambarkan dengan diagram alir sebagai berikut: 


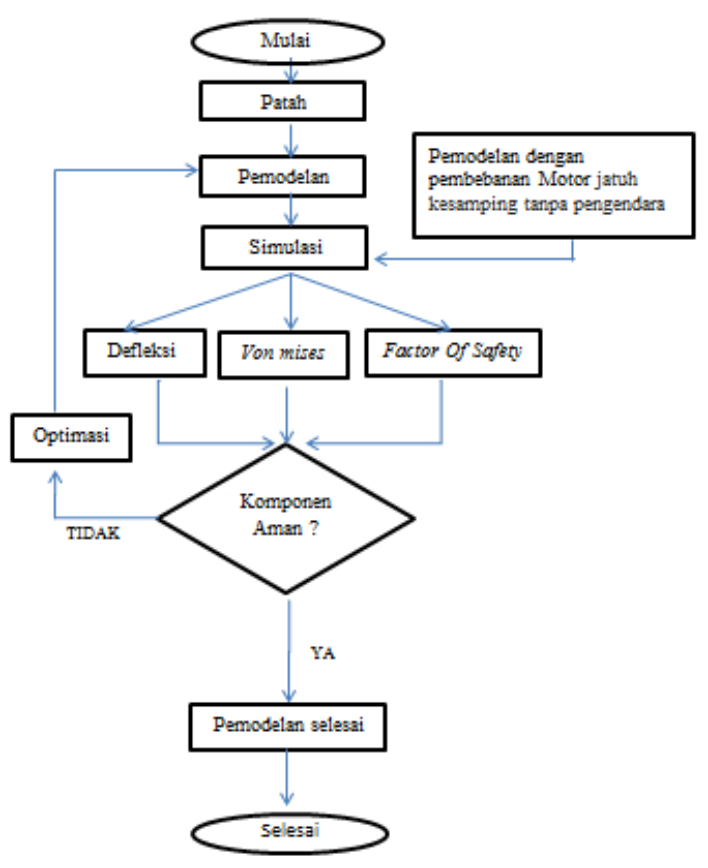

Gambar 3. Diagram alir proses analisa Autodesk Inventor Profesional 2014

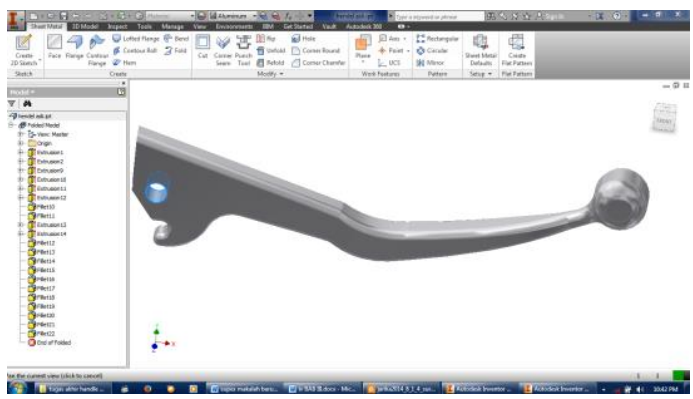

Gambar 4. proses analisa menggunakan Autodesk Inventor Profesional 2014

Pembebanan yang diberikan saat menjalankan simulasi diambil berat motor Yamaha V-Ixion yaitu $129 \mathrm{~kg}$. Pembebanan pemodelan handle pengendara diasumsikan dimana kondisi handle terikat pada baut frame sepeda motor. Lokasi fixed constraints seperti terlihat pada Gambar 5 yang digambarkan warna tanda panah.

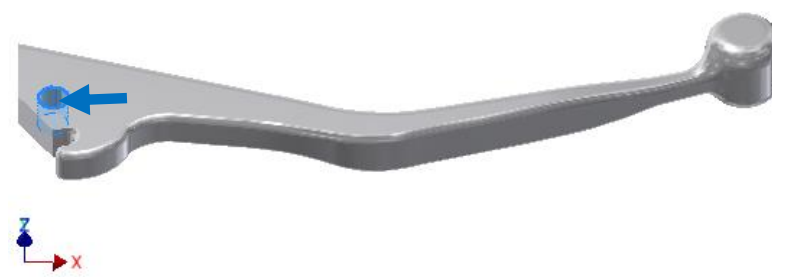

Gambar 5. Lokasi fixed constraints
Tabel 1 Jenis pembebanan yang di terima handle.

\begin{tabular}{lll}
\hline $\begin{array}{l}\text { Jenis } \\
\text { pembebanan }\end{array}$ & $\begin{array}{l}\text { Keterangan } \\
\text { beban yang } \\
\text { diterima } \\
(\mathbf{k g})\end{array}$ & $\begin{array}{l}\text { Total } \\
\text { pembebanan } \\
(\mathbf{N})\end{array}$ \\
\hline $\begin{array}{l}\text { Motor jatuh } \\
\text { ke samping }\end{array}$ & $\begin{array}{l}\text { Beban motor } \\
129\end{array}$ & 1265,4 \\
\hline
\end{tabular}

Kondisi pembebanan yang di lakukan pada handle ditunjukkan pada gambar 6 .

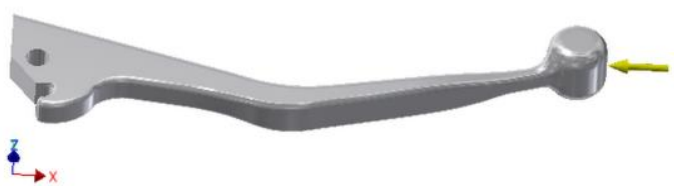

Gambar 6. pembebanan dengan kondisi pada handle mengalami benturan

\section{HASIL DAN PEMBAHASAN}

Setelah di lakukan pemodelan, penggunaan material, pembebanan dan mers area, maka selanjutnya akan di bahas tentang hasil pemodelan simulasi Autodesk Inventor Professional 2014, yang meliputi analisa tegangan von mises, diplacement dan faktor keamanan. Hasil tegangan di tunjukan pada gambar berikut:

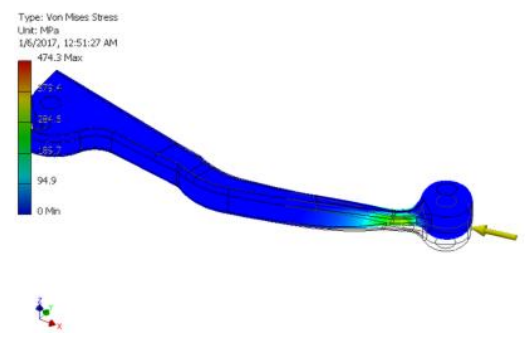

Gambar 7. hasil Tegangan von mises

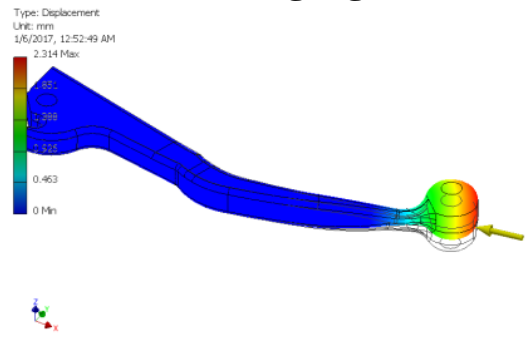

Gambar 8. Hasil displacement 


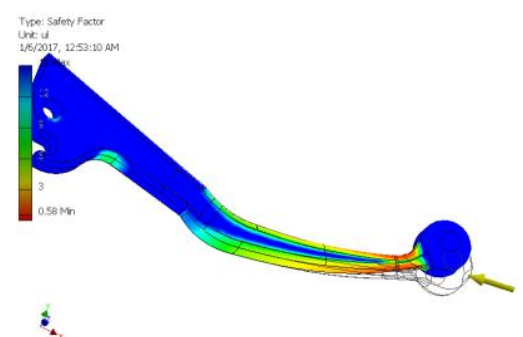

\section{Gambar 9 Faktor keamanan handle}

Sehingga hasil von mises displacement dan faktor keamanan berturut turut 473,3 Mpa, 2,314 $\mathrm{mm}$ dan 0,58 . Hasil faktor keamanan yang lebih kecil dari faktor keamanan yang diizinkan sehingga rawan akan kegagalan.

Tabel 2 Hasil pemodelan handle asli diperoleh tegangan dari simulasi Autodesk Inventor Professional 2014

\begin{tabular}{lclc}
\hline $\begin{array}{c}\text { Kondisi } \\
\text { pembebanan }\end{array}$ & $\begin{array}{c}\text { Von } \\
\text { mises } \\
\text { stress } \\
\text { (MPA) }\end{array}$ & $\begin{array}{c}\text { Displaceme } \\
\boldsymbol{n t}(\mathbf{m m})\end{array}$ & $\begin{array}{c}\text { Faktor } \\
\text { keamanan }\end{array}$ \\
\hline $\begin{array}{l}\text { Motor jatuh } \\
\text { ke samping }\end{array}$ & 474,3 & 2,314 & 0,58 \\
\hline
\end{tabular}

\section{Optimasi desain handle}

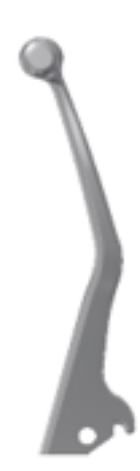

(a)

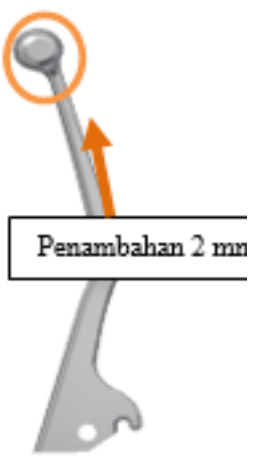

(b)
Gambar 10 (a) hasil pemodelan handle asli (b) penambahan radius melingkar rawan patah $2 \mathrm{~mm}$

Penambahan optimasi $2 \mathrm{~mm}$ pada bagian rawan kegagalan. Tanda panah menunjukkan penambahan pada bagian rawan patah. di tunjukkan seperti Gambar 10. Hasil penambahan rawan patah $2 \mathrm{~mm}$ terlihat pada Gambar 11 - 13 .

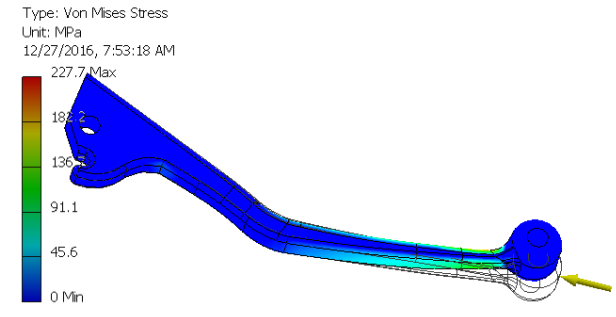

Gambar 11 Hasil tegangan von mises dari simulasi di mana handle motor jatuh ke samping penambahan $2 \mathrm{~mm}$

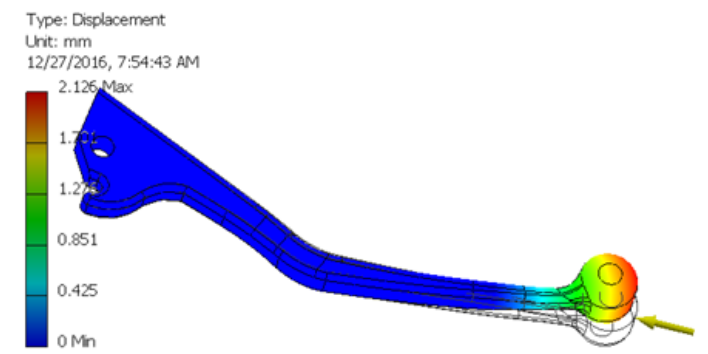

Gambar 12 Hasil displacement dari simulasi dimana handle jatuh ke samping, penambahan rawan patah $2 \mathrm{~mm}$

Type: Safety Facto

Unit: 4

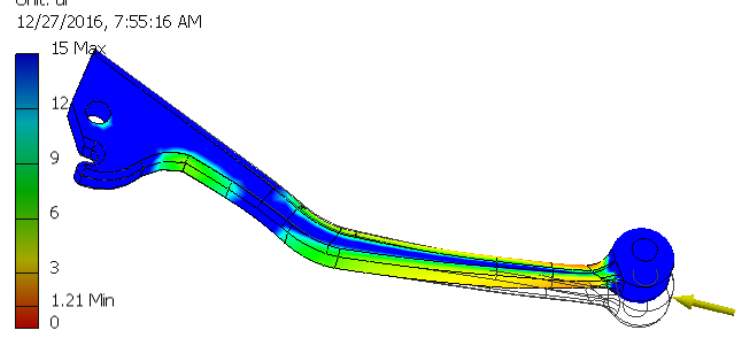

Gambar 13 Hasil faktor keamanan dari simulasi dimana handle jatuh ke samping, penambahan rawan patah $2 \mathrm{~mm}$

Optimasi penambahan radius $2 \mathrm{~mm}$ pada daerah rawan patah, kemudian dilakukan simulasi, maka didapatkan nilai faktor keamanan yang lebih tinggi dari nilai faktor keamanan pabrikan dan di atas nilai faktor keamanan yang diizinkan yaitu 1,0(Irawan, 2009) sehingga aman untuk digunakan.

\section{Tabel 2 Hasil optimasi 2 mm}

\begin{tabular}{lccc}
\hline $\begin{array}{l}\text { Kondisi } \\
\text { pembebanan }\end{array}$ & $\begin{array}{l}\text { Von } \\
\text { mises } \\
\text { stress } \\
(\mathbf{M p a})\end{array}$ & $\begin{array}{l}\text { Displace } \\
\text { ment } \\
(\mathbf{m m})\end{array}$ & $\begin{array}{l}\text { Faktor } \\
\text { keamanan }\end{array}$ \\
\hline $\begin{array}{l}\text { Motor jatuh ke } \\
\text { samping }\end{array}$ & 27,7 & 2,126 & 1,21 \\
\hline
\end{tabular}


Dimana pada tabel 2 menunjukkan hasil optimasi, semakin di tambah radius di area rawan patah maka faktor keamanan menjadi meningkat dari desain pabrikan, dengan penambahan ketebalan $2 \mathrm{~mm}$. Pada simulasi didapatkan nilai faktor keamanan yang lebih tinggi dari 1 maka dari simulasi disimpulkan penambahan pada ketebalan $2 \mathrm{~mm}$ aman digunakan. Faktor keamanan ini sudah sesuai daya setandar untuk material. Menurut (Irawan, 2009) $\mathrm{FS}=1,0$ jika properti material diketahui. Jika secara eksperimental diperoleh dari pengujian spesimen.

\section{KESIMPULAN}

Tegangan yang terjadi dalam kondisi pembebanan handle motor jatuh ke samping Dengan kondisi tersebut kemudian dilakukan simulasi sehingga dari hasil simulasi didapatkan tegangan von mises 474,3 Mpa. Defleksi yang terjadi dalam kondisi motor jatuh ke samping. Dengan kondisi tersebut kemudian dilakukan simulasi sehingga dari hasil simulasi didapatkan tegangan 2,314 $\mathrm{mm}$.

Faktor keamanan pada kondisi pembebanan motor jatuh ke samping. Dengan kondisi tersebut kemudian dilakukan simulasi sehingga dari hasil simulasi didapatkan faktor keamanan 0,58. Dimana faktor keamanan kurang dari 1 sehingga pada kondisi motor jatuh ke samping rawan patah.

Optimasi penambahan ketebalan $1 \mathrm{~mm}$ dari desain pabrikan di posisi bagian permukaan rawan patah von mises stress, displacement dan faktor keamanan berturutturut 338,6 Mpa, 2,007 dan 0,81. Nilai faktor keamanan yang lebih rendah dari pada 1 . Optimasi penambahan ketebalan $2 \mathrm{~mm}$ pada permukaan yang rawan patah. Sehingga di dapatkan hasil von mises stress, displacement dan faktor keamanan berturut-turut 227,7 Mpa, 2,126 dan 1,21 . Sehingga seperti hasil simulasi setelah optimasi penambahan ketebalan, mendapatkan faktor keamanan lebih dari 1 di dapatkan 1,21 maka di simpulkan penambahan $2 \mathrm{~mm}$ aman di gunakan.

\section{DAFTAR PUSTAKA}

Hardiyansyah M., 2016, Analisis Tegangan, Defleksi Dan Faktor Keamanan Pada Pemodelan Footrest Sepeda Motor Honda Scoopy Dengan Aplikasi Autodesk Inventor Berbasis Elemen Hingga. UNWAHAS. Semarang.
Irawan A. P., 2009, Diktat Elemen Mesin, Universitas Tarumanagara, Jakarta.

Irfan, 2015, Pengalaman Pertama Yamaha New Vixion Ambruk Handle Rem Patah, http; Petamax7.com.

Ismail M.A.D., 2016 Analisis Footstep Holder Sepeda Motor Kawasaki KLX BF dengan aplikasi Autodesk Inventor Bebasis Simulasi Elemen hingga. UNWAHAS. Semarang.

Ismawanto dkk., 2014, Simulasi kekuatan material Pada Carabiner Dengan Variasi Geometri. Universitas Lampung

James M. G., 2004, Mechanics of Materials, eighth edition, Thomson Learning Academic Resource Center 1-800-4230563.

Khurmi R. S., and Gupta J.K., 2005, Machine Design, Eurasia Publishing House (PVT.) LTD. Ram Nagar, New Delhi110055.

Nakasone Y., and Yoshimoto S., 2006, Engineering Analisys With Ansys Software, Elsevier's Science and Technology Right Department in Oxford.

Tawancy H.M., Hamid A. U., and Abbas N. M., 2004, Practical Engineering Failure Analisys, Marcel Dekker, Inc., 270 Madison Avenue, New York, NY 10016, U.S.A.

Waguespack C., 2013, Mastering Autodesk Inventor 2014 and Autodesk LT 2013, John Wiley \& Sons, Inc., 111 River Street, Hoboken, NJ 07030.

Weaver J.R.W., dan Paul R.J., 1993, Finite Elements for Structural Analysis (Elemen Hingga untuk Analisis Struktur) Terjemahan oleh Markus Rubijanto Kusuma. Bandung: PT. Eresco.

Yamaha, 2016, Spesifikasi Motor Yamaha v-ixion, www.Yamaha.com. 